\title{
Paraplegia
}

\section{Stone Surgery in the Spinal Patient}

\author{
P.P. Irwin, ${ }^{1}$ C. Evans, ${ }^{1}$ J.C. Chawla, ${ }^{2}$ P.N. Matthews ${ }^{1}$ \\ ${ }^{I}$ Department of Urology, Cardiff Royal Infirmary, ${ }^{2}$ Spinal Injury Unit, Rookwood \\ Hospital, Cardiff, Wales.
}

\begin{abstract}
Summary
The initial treatment of renal calculi in 16 patients with spinal disorders is reviewed. A total of 18 kidneys in 11 patients with congenital spina bifida $(S B)$ and 5 with spinal cord injury (SCI) were treated. The mean stone burden per kidney was $3.4 \mathrm{cms}$ and 1.9 cms for the SB and SI groups respectively. Complete stone clearance was obtained in 5 of 7 open operations (71\%) and in 7 of 10 cases by percutaneous nephrolithotomy (70\%). One kidney received extracorporeal shock wave lithotripsy as the initial treatment. The complication rate was significantly greater in cases treated by open surgery. It is suggested that percutaneous surgery is the preferred initial treatment of renal stones in the spinal patient.
\end{abstract}

Key words: Renal calculi; Spinal paralysis; Percutaneous nephrolithotomy; Extracorporeal shock wave lithotripsy.

The management of the spinal patient with renal stones is a challenge to the whole urological team. Partial or complete immobility affects transport arrangements and great demands may be placed on nursing staff who take care of their feeding, hygiene and pressure areas. Spinal patients tend to have unusually large stone burdens and the rate of stone recurrence is high (Lazare et al., 1988). Surgical management may be hampered by skeletal deformity or by altered anatomy resulting from previous surgery to the renal tract. The high incidence of bacteruria in these patients (Kohli and Hamid, 1986) increases the risk of perioperative septic complications. In the light of the recent advances in the treatment of urolithiasis, we reviewed the initial management of renal stones in spinal patients in Cardiff since 1984.

Correspondence to: Mr P.N. Matthews, Department of Urology, Cardiff Royal Infirmary, Newport Road, Cardiff, Wales.

This paper was presented as a poster at the annual meeting of the British Association of Urological Surgeons in Jersey, June 1989. 


\section{Patients and methods}

Sixteen spinal patients have been treated for renal calculi in Cardiff since 1985. Eleven patients had congenital spina bifida (SB) and 5 had previous spinal cord injury (SCI). Most patients had had previous surgery to the urinary tract and 8 had previous urinary diversions. These details and the indications for surgery are shown in Table I. A total of 18 kidneys were treated. The mean stone burden (MSB) was calculated as the mean of the largest and smallest diameters of each calculus, and in the case of multiple stones, the MSB of each was added. The average MSB per kidney was $3.4 \mathrm{cms}$ for SB patients and $1.9 \mathrm{cms}$ in the case of the SCI group. Eight kidneys contained staghorn calculi and multiple stones were present in 4 . The left kidney was affected in 10 patients and stones were bilateral in 1 .

Pre-operative urine specimens were infected in 3 cases. However, every patient received parenteral antibiotics both immediately pre-operatively and for varying durations after surgery.

Open surgery was carried out on a total of 7 kidneys; one of these was a nephrectomy for a poorly functioning infected kidney. Percutaneous nephrolithotomy (PCN) was introduced to our unit in 1987 and as experience with this technique improved, became the preferred initial treatment for renal calculi. Ten kidneys in this series received PCN. The kidney was punctured by the same radiologist (CE) in all cases. In undiverted patients a cystoscopy and retrograde was carried out under the same general anaesthesic prior to percutaneous puncture. In patients with diversions an antegrade puncture was performed under local anaesthetic (if needed) in the X-ray department the day before surgery. In one case, a SB patient with a staghorn calculus, PCN was abandoned due to equipment failure; an open operation was performed at a later date. One kidney with a staghorn calculus received ESWL as its initial treatment, a double-J stent having been inserted beforehand.

\section{Results}

The results of treatment are illustrated in the management algorhythm (Table I).

Table I Summary of management, results and follow-up

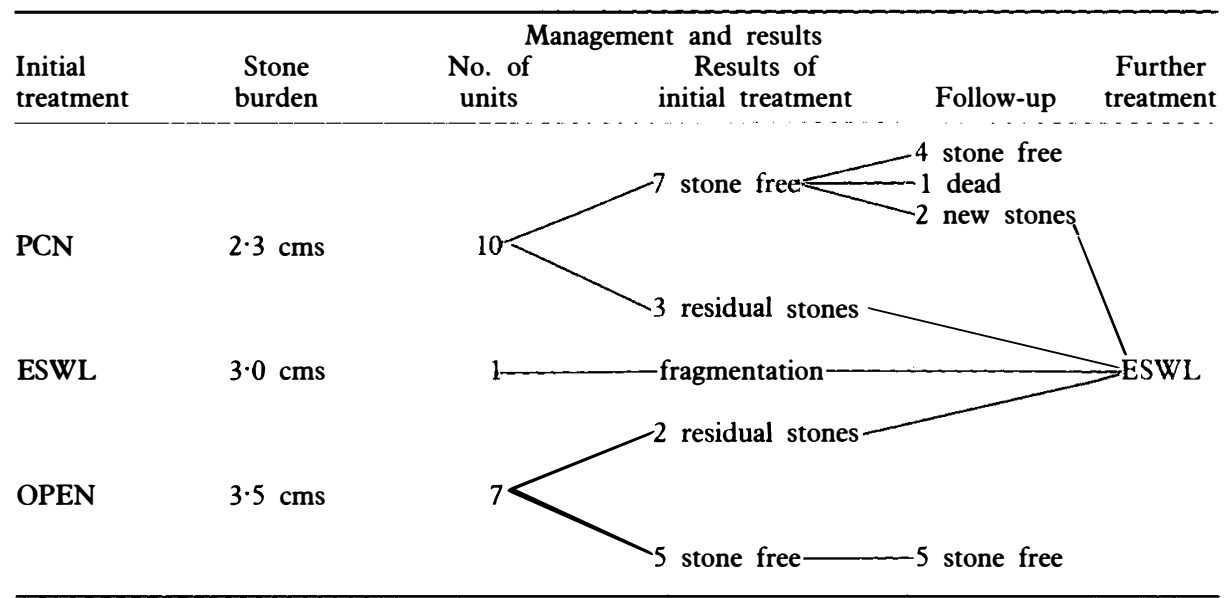


Open procedures were employed before the PCN service became fully operational (in 1987), and with increasing experience PCN became the initial treatment of choice. Open procedures were generally employed for larger renal stones; the mean stone burden per unit was $3.5 \mathrm{cms}$, compared with $2.3 \mathrm{cms}$ in cases where PCN was used. The initial complete stone clearance rate, however, was similar for each procedure (Table II). ESWL successfully fragmented a single $3 \mathrm{cms}$ staghorn calculus, but several treatment sessions on the lithotripter were subsequently required to obtain partial clearance.

Table II Comparison of initial stone clearance and recurrence rates

\begin{tabular}{lcc}
\hline & Initial clearance & Recurrence rate \\
\hline Open operation & $5 / 7(71 \%)$ & 0 \\
PCN & $7 / 10(70 \%)$ & $2(20 \%)$ \\
\hline
\end{tabular}

Table III PCN v Open operations

\begin{tabular}{lcc}
\hline & PCN & Open operations \\
\hline MSB & $2 \cdot 3 \mathrm{cms}$ & $3 \cdot 5 \mathrm{cms}$ \\
Anaesthetic time & $120 \mathrm{mins}$ & $180 \mathrm{mins}$ \\
Blood transfusion & 0 patients & 4 patients \\
Hospital stay & 7 days & 22 days \\
& (Range $5-14$ days) & (Range $8-60$ days)
\end{tabular}

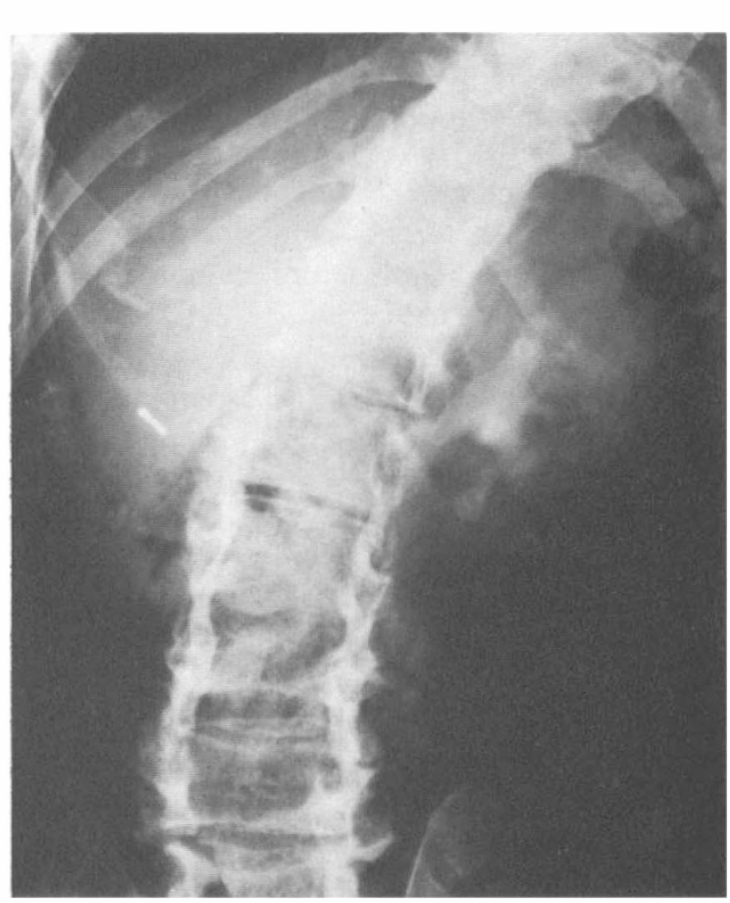

Figure 1 Staghorn calculus in a spina bifida patient. This was debulked percutaneously, leaving a small $(<1 \mathrm{~cm})$ fragment to be treated by ESWL. 
Except for one case, in whom the stone could not be visualised endoscopically, PCN had no operative problems and was usually performed within an average anaesthetic time of 120 minutes (Table III). Open procedures took an average of 180 minutes and were associated with more complications, including one SB boy who had a severe haemorrhage from a horseshoe kidney (Table IV). Blood transfusion was required in 4 patients; all of these were SB who had open operations. Postoperative pain was a problem in only 4 patients (all SB), 3 of whom had open operations. None of the SI group required any post-operative analgesia. Two patients, both $\mathrm{SB}$, who had open operations developed severe sacral pressure scores which required plastic surgery. There were no serious post-operative complications in the PCN group. However, all 16 patients had a pyrexia in the early post-operative

Table IV Complications

\begin{tabular}{lll}
\hline & PCN & Open \\
\hline Haemorrhage & 0 & $1(\mathrm{SB})$ \\
Pain & $1(\mathrm{SB})$ & $3(\mathrm{SB})$ \\
Pressures sores & 0 & $2(\mathrm{SB})$ \\
Wound infection & 0 & $2(\mathrm{SB})$ \\
UTI & $1(\mathrm{SB})$ & $2(\mathrm{SB}+\mathrm{SI})$ \\
\hline
\end{tabular}

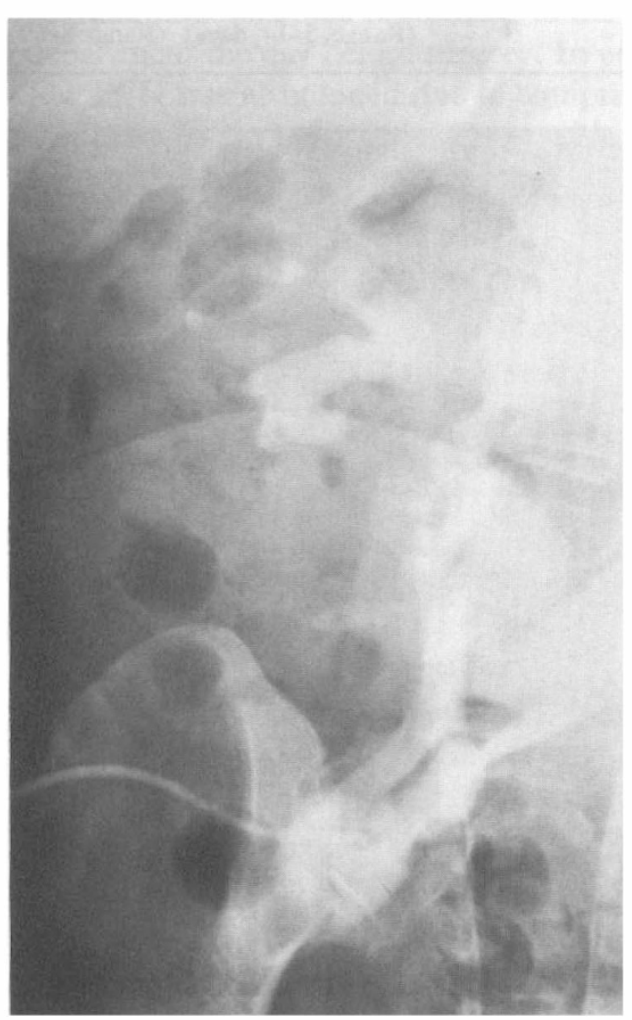

Figure 2 Staghorn calculus and ileal conduit in a spina bifida patient. PCN was abandoned for technical reasons and the stone was later successfully removed by open operation. 
period; this was transient in all except 5 who developed overt sepsis (wound and urinary tract infections).

\section{Follow-up}

One of our patients died, having failed to attend the follow-up clinic; the cause of death is not known. The remaining patients have been reviewed for periods varying from 6 months to 4 years after initial treatment. The average follow-up period was $24 \cdot 3$ months. Plain abdominal X-rays (KUB) and urine microscopy were routinely performed at each clinic visit. Nine kidneys were free of calculi without requiring any further therapy. Five kidneys received ESWL to treat residual stone fragments, while the patient with a staghorn calculus who received ESWL as initial treatment needed two further treatment sessions. Nine patients were free of calculi without requiring any further therapy. None of the 5 cases who were rendered stone free by open operation developed new stones. New stone formation was detected in two kidneys, 12 months and 19 months respectively, following PCN. These have since been referred for ESWL.

Despite successful stone removal, all patients continued to have persistent bacteruria and occasional frank urinary tract infections.

\section{Discussion}

Spinal patients are at an increased risk of developing renal stones; the estimated incidence in patients with spinal injuries is $8 \%$ (De Vivo et al., 1984). Stones tend to grow rapidly and often reach great sizes without causing any symptoms, although in the long term they cause considerable morbidity (Gardner et al., 1985). Persistent pain, recurrent urinary tract infections and deteriorating renal function are the main indications for surgery (Wickham, 1980; Straffon and Higgins, 1970). The increased availability of PCN and ESWL in most modern centres has now made earlier active intervention possible (Gardner et al., 1985).

In our series, similar complete initial stone clearance rates were achieved with both open operation and PCN. The recurrence rate was lower in the open group, none of whom developed new stones in the follow-up period. However, such success was achieved at the expense of longer anaesthetic time, increased blood loss and a significantly greater complication rate. Our clearance rates compare very favourably with those obtained for similar sized stones in the able-bodied population. Charig et al (1986) achieved $71 \%$ and $69 \%$ success rates at 3 months for open operations and PCN respectively.

It is interesting to note that practically all complications were confined to the SB group of patients. This is probably related to the greater stone burdens, the effect of previous surgical procedures on the renal tract and the greater skeletal deformities which these patients have. The high incidence of persistent bacteruria and recurrent infections in patients who had been rendered completely stone free was disappointing; this may have been due to urinary stasis, bladder catherisation or to the presence of microcalculi which would not have been detected by X-ray. Eight of our patients were referred for ESWL. It is anticipated that greater demand will be placed on the lithotripter service by such patients in the future. However, not all patients with spinal defects are suitable for ESWL as the kidney may lie over the 
spinal column or be completely shielded by a deformed spine and rib cage. Our current policy for the management of renal stones in our spinal patients - initial percutaneous debulking, leaving ESWL to treat residual fragments - will continue. ESWL is a technique which offers a quick, relatively painless and very effective means of managing such small stones (Charig et al., 1986). Open operations will be reserved for patients in whom percutaneous surgery fails. Close follow-up of all patients with spinal defects is strongly recommended as ESWL is now a very suitable treatment for those with small stones.

\section{Acknowledgement}

We are indebted to Miss Carolyn Morgan, Department of Surgery, Cardiff Royal Infirmary, for her time and perfection in typing this article. We also thank Mr R.W.N. Rees and Mr T.P. Stephenson for allowing us to include their patients in this review.

\section{References}

Charig CR, Webb DR, PAyne SR, WiCkham JEA 1986 Comparison of the treatment of renal calculi by open surgery, percutaneous nephrolithotomy, and extracorporeal shockwave lithotripsy. British Medical Fournal 292:879-882.

DE Vivo MJ, Fine PR, CuTter GR, MAETZ HM 1984 The risk of renal calculi in spinal cord injury patients. Fournal of Urology 131:857-860.

GARDNER BP, PARSONS KF, SONI BM, KRISHNAN KR 1985 The management of upper urinary tract calculi in spinal cord damaged patients. Paraplegia 23:371-378.

KOHLI A, LAMID S 1986 Risk factors for renal stone formation in patients with spinal cord injury. British Fournal of Urology 58:588-591.

LAZARE JN, SALTZMAN B, SotolONGo J 1988 Extracorporeal shockwave lithotripsy treatment of spinal cord injury patients. Fournal of Urology 140:266-269.

STRAFFON RA, Higgins CC 1970 In: Cambell MF, Harrison JH eds. Urology, Third edition. Volume I. Chapter 18, p. 734.

WICKHAM JEA 1980 In: Urology, ed, Chisholm GD. 1st edn Chapter 10, p 132. 